\title{
КОРРОЗИЯ НЕРЖАВЕЮЩИХ СТАЛЕЙ В ХЛОРСОДЕРЖАЩИХ ДЕЗИНФИЦИРУЮЩИХ РАСТВОРАХ
}

\section{А. В. Поспелов ${ }^{1}$, А. А. Касач², Е. В. Романовская ${ }^{3}$, В. И. Романовский4}

\author{
${ }^{1}$ Младший научный сотрудник, Центр физико-химических методов исследований, \\ Белорусский государственный технологический университет, Минск, Беларусь, e-mail: andrei29088@таil.ru \\ ${ }^{2}$ Младший научный сотрудник, каф. химии, технологии электрохимических производств и материалов электронной техники, \\ Белорусский государственный технологический университет, Минск, Беларусь, e-mail: kasach2018@bk.ru \\ ${ }^{3}$ К. х. н., старший преподаватель, каф. химии, технологии электрохимических производств и материалов электронной техники, \\ Белорусский государственный технологический университет, Минск, Беларусь, e-mail: helb@yandex.ru \\ ${ }^{4}$ K. m. н., старший научный сотрудник Института общей и неорганической химии \\ Национальной академии наук Беларуси, Минск, Беларусь, e-mail: v.romanovski@yandex.ru
}

\begin{abstract}
Ресрерат
Представлены результаты по коррозионной устойчивости нержавеющих сталей 304 и 316 в 2 \% растворах хлорсодержащих дезинфицирующих веществ. Для анализа использовались определения потенциалов разомкнутой цепи от времени выдержки и измерение токов коррозии. Изменение состава и морфологии обрабатываемых поверхностей изучали с помощью сканирующей электронной микроскопии с элементным анализом.
\end{abstract}

Ключевые слова: коррозия, сталь нержавеющая, растворы хлорсодержащие дезинфицирующие, потенциал разомкнутой цепи, микроскопия электронная сканирующая, элементный анализ.

\section{CORROSION OF STAINLESS STEELS IN CHLORINE-CONTAINING DISINFECTANT SOLUTIONS}

\section{Abstract}

\section{A. V. Pospelov, A. A. Kasach, E. V. Romanovskaia, V. I. Romanovski}

The results on the corrosion resistance of stainless steels 304 and 316 in $2 \%$ solutions of chlorine-containing disinfectants are presented. For analysis, we used the definition of open-circuit potentials from the exposure time and the measurement of corrosion currents. The change in the composition and morphology of the treated surfaces was studied using scanning electron microscopy with elemental analysis.

Keywords: corrosion, stainless steel, chlorine-containing disinfectant solutions, open-circuit potential, electron scanning microscopy, elemental analysis.

\section{Введение}

С целью поддержания санитарно-гигиенических норм на предприятиях пищевой промышленности, а также в учреждениях здравоохранения производят дезинфекцию рабочих поверхностей. В настоящее время для этих целей используются хлорсодержащие дезинфицирующее агенты (жидкий хлор, гипохлорит кальция и натрия, хлорамин диоксид хлора). Механизм антимикробного воздействия хлорсодержащих соединений обусловлен сильным окислительным воздействием на мембрану клетки.

К достоинствам хлорсодержащих дезинфиицирующих растворов следует отнести: эффективность в отношении широкого спектра различных бактерий, грибков и вирусов; экономической и практической доступности; незначительное влияние жесткости воды на дезинфицирующую активность хлора в растворе. Для эффективной дезинфекции рабочих поверхностей используют хлорсодержащие растворы С концентрацией активного хлора от 50 мг/дм³ до $5 \%$ растворов.

Ранее были проведены исследования по оценке коррозионного воздействия хлорсодержащих дезинфицирующих растворов на углеродистые стали, используемые в системах водоснабжения [1-4] проведен сравнительный анализ использования хлорсодержащих растворов и растворов озона в воде: проведен технический [5-10], экономический [11] и экологический анализ [4, 11].

Однако хлорсодеражщие среды могут оказывать сильное коррозионное воздействие на изделия, изготовленные из металлов и их сплавов. В результате коррозии на поверхности металла могут образовываться различные дефекты (трещины, питтинги, механические неровности и т. д). Поскольку дезинфектанты не обладают высокой проникающей способностью, микроорганизмы в трещинах, царапинах могут быть не полностью уничтожены после обработки, что приводит к необходимости оценки коррозионного воздействия дезинфицирующих агентов на металлы и их сплавы.

Преимущественно на предприятиях пищевой промышленности, а также в учреждениях здравоохранения материалами для изготовления поручней, различных емкостей, резервуаров, систем водоснабжения и водоотведения используют нержавеющие стали марок AISI 304 и AISI 316. Данные стали для улучшения физико-механических Машиностроение doi.org/10.36773/1818-1212-2021-125-2-63-65 коррозионных свойств легируют $\mathrm{Ni}, \mathrm{Cr}$, Мо и т. д. [12, 13]. Известно, что ионы никеля и хрома обладают сильными аллергенными свойствами по отношению к организму человека. В результате коррозии сплава под воздействием хлорсодержащей среды ионы никеля и хрома могут высвобождаться, что может являться потенциальной угрозой здоровью человека [14].

Для точного измерения скорости коррозии металлов применяются длительные эксплуатационные коррозионные испытания (от года до нескольких лет). Для более быстрой оценки коррозионного поведения металлических материалов используются электрохимические методы измерения. С помощью линейной вольтамперометрии можно измерить плотность тока коррозии, что в свою очередь является скоростью процесса.

Целью данной работы является исследование коррозионного поведения сталей AISI 304 и AISI 316 в хлорсодержащих дезинфецирующих растворах.

\section{Методология исследования}

В данной работе объектами исследования служили стали марок AISI 304 и AISI 316. Состав используемых сплавов представлен в таблице 1.

Таблица 1 - Элементный состав сталей согласно стандартам

\begin{tabular}{|c|c|c|c|c|c|c|c|c|c|}
\hline \multicolumn{10}{|c|}{ AISI 304, элементный состав масс.\% } \\
\hline $\mathrm{Fe}$ & $\mathrm{Ni}$ & $\mathrm{Cr}$ & \begin{tabular}{l|l}
$\mathrm{Si}$ \\
\end{tabular} & & $\mathrm{Mn}$ & & S & $P$ & C \\
\hline өланс & $8-10,5$ & $18-20$ & $<1,0$ & & $<2,0$ & & 0,03 & $<0,045$ & $<0,0$ \\
\hline \multicolumn{10}{|c|}{ AISI 316, элементный состав масс.\% } \\
\hline $\mathrm{Fe}$ & $\mathrm{Ni}$ & $\mathrm{Cr}$ & \begin{tabular}{l|l}
$\mathrm{Si}$ & \\
\end{tabular} & & & & $\mathrm{S}$ & $P$ & C \\
\hline аланс & 10-14 & $6-18$ & $<0,75$ & $2-3$ & & & $<0,0$ & $<0,045$ & $<0,0$ \\
\hline
\end{tabular}

Перед проведением испытаний стальные образцы шлифовали в водной среде с использованием наждачной бумаги Р250, P500, P800, P1200 и P2000. После операции шлифовки все образцы тщательно обезжиривали в этаноле. В качестве дезинфицирующих сред использовали водные растворы хлорамина, гипохлорита калия и кальцийсодержащие $2 \%$ активного хлора. 
В качестве дезинфицирующих хлорсодержащих веществ выбраны гипохлорит кальция и натрия, а также хлорамин. С концентрацией активного хлора $2 \%$. Исследуемые растворы готовились на основе искусственной питьевой воды согласно ISO 6341 : 2012 с pH 7,5. Концентрация растворов гипохлоритов $2 \%$ по активному хлору.

Электрохимические исследования проводили на потенциостате/гальваностате Elins p 40x в стандартной трехэлектродной ячейке. В качестве электрода сравнения использовали хлоридсеребряный электрод. Вспомогательным электродом служила платиновая сетка. Площадь рабочего электрода во всех исследованиях составляла $1 \mathrm{~cm}^{2}$ Поляризационные кривые снимались в диапазоне потенциалов от 300 мВ до +300 мВ относительно стационарного потенциала при скорости развертки потенциала $1 \mathrm{mB} / \mathrm{c}$. Все значения потенциалов пересчитаны в шкалу стандартного водородного электрода. Тафелевские угль наклона поляризационных кривых, токи обмена и коррозии для исследуемых систем определяли с применением ПО «NOVA 2.11».

Микроструктуру и элементный состав поверхности исследуемых образцов сталей до и после выдержки в коррозионной среде изучали методами сканирующей электронной микроскопии и энергодисперсионного рентгеновского анализа (EDX) с помощью сканирующего электронного микроскопа JSM-5610 LV, оснащенного системой химического микрорентгеноспектрального анализа EDX JED-2201.

\section{Результаты исследований}

Ниже представлены зависимости потенциалов разомкнутой цепи от времени выдержки в хлорсодержащих средах для стали AISI 304 (рис. 1) и стали AISI 316 (рис. 2). В дезинфицирующем растворе на основе $\mathrm{Ca}(\mathrm{ClO})_{2}$ (рис.1 кривая 1) стабилизация потенциала происходит в течение первых 5 минут, далее наблюдается монотонное увлечение электродного потенциала во времени. В случае растворов на основе $\mathrm{NH}_{2} \mathrm{Cl}$ (рис. 1 кривая 2) и $\mathrm{NaClO}$ (рис. 1 кривая 2) стабилизация потенциала осуществляется медленнее и происходит в течение 15 мин в сторону уменьшения значений. Также для данных растворов изменение электродного потенциала от времени экспозиции незначительно и после стабилизации составляет около 0.26 В, что на $16 \%$ ниже значений для раствора $\mathrm{Ca}(\mathrm{ClO})_{2}$.

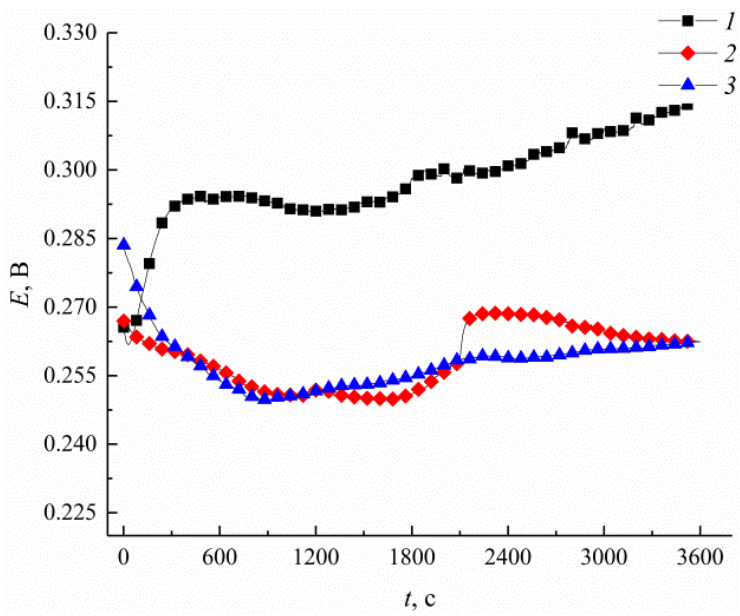

$1-\mathrm{Ca}(\mathrm{ClO}) 2 ; 2-\mathrm{NH}_{2} \mathrm{Cl} ; 3-\mathrm{NaClO}$

Рисунок 1 - Зависимость потенциала разомкнутой цепи AISI 304 от времени экспозиции в хлорсодержащих средах

При выдержке образцов стали AISI 316 во всех исследуемых растворах наблюдается монотонное увеличение потенциалов во времени в электроположительную сторону. Необходимо отметить, что наименьшие значения потенциала разомкнутой цепи наблюдается для образца, погруженного в раствор хлорамина (рис. 2 кривая 2).

Полученные данные свидетельствуют о том, что сталь AISI 316 является более устойчивой в исследуемых $2 \%$ растворах хлорсодержащих дезинфицирующих веществ в сравнении со сталью AISI 304

После одного цикла обработки сталей на микрофотографиях с увеличением до 5000 крат не было выявлено видимых изменений в микроструктуре поверхности. В таблице 3 представлены данные EDX анализа поверхности сталей после 1 цикла дезинфекции исследуемыми растворами в течение 30 мин.

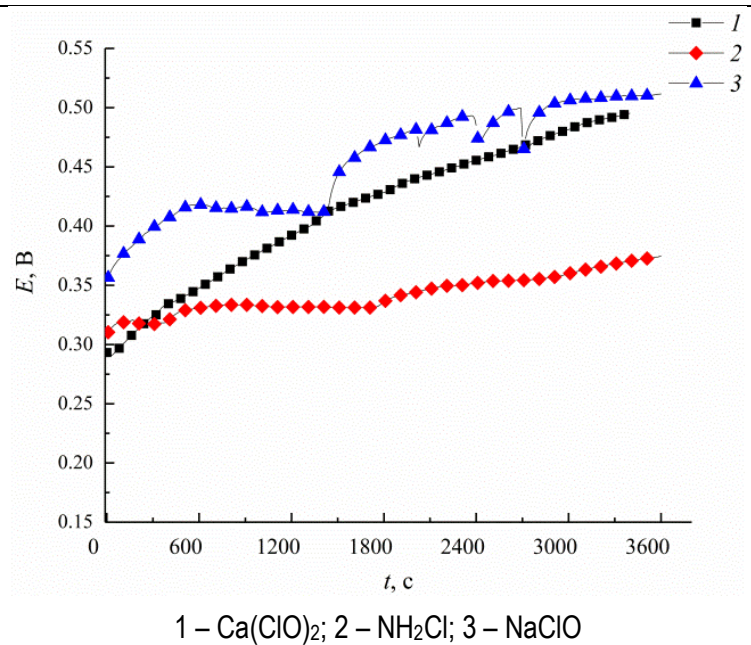

Рисунок 2 - Зависимость потенциала разомкнутой цепи AISI 316 от времени экспозиции в хлорсодержащих средах

B таблице 2 представлены токи коррозии образцов сталей AISI 304 и AISI 316 в исследуемых растворах. Полученные данные также подтверждают более высокую коррозионную стойкость стали марки AISI 316 в исследуемых растворах. Наименьшая коррозионная устойчивость наблюдается для стали марки AISI 304 в растворе $\mathrm{NaClO}$, а для стали марки AISI 316 в растворе $\mathrm{NH}_{2} \mathrm{Cl}$. Более высокая коррозионная устойчивость нержавеющей стали марки AISI 316 обусловлена за счет ее дополнительного легирования молибденом.

Таблица 2 - Токи коррозии образцов сталей AISI 304 и AISI 316 в дезинфиицирующих растворах

\begin{tabular}{|c|c|c|}
\hline \multirow{2}{*}{ Раствор } & \multicolumn{2}{|c|}{ Плотность тока коррозии, $\mathrm{MкA} / \mathrm{cm}^{2}$} \\
\cline { 2 - 3 } & AlSI 304 & AISI 316 \\
\hline $\mathrm{NaClO}$ & $0,143 \cdot 10^{-8}$ & $3,23 \cdot 10^{-8}$ \\
\hline $\mathrm{NH}{ }_{2} \mathrm{Cl}$ & $9,43 \cdot 10^{-8}$ & $7,10 \cdot 10^{-8}$ \\
\hline $\mathrm{Ca}(\mathrm{ClO})_{2}$ & $9,43 \cdot 10^{-8}$ & $2,85 \cdot 10^{-8}$ \\
\hline
\end{tabular}

Таблица 3 - Элементные составы сталей марок AISI 304 и AISI 316 после 1 цикла обработки в исследуемых растворах

\begin{tabular}{|c|c|c|c|c|}
\multicolumn{5}{c|}{ после 1 цикла обработки в исследуемых растворах } \\
\hline \multirow{3}{*}{ Елемент Сталь AISI 304} \\
\cline { 2 - 5 } & \multirow{5}{*}{ Содержание элементов, мас.\% } \\
\cline { 2 - 5 } & До обработки & \multicolumn{4}{|c|}{ После обработки } \\
\cline { 2 - 5 } & $\mathrm{NaClO}$ & $\mathrm{Ca}(\mathrm{ClO}) 2$ & $\mathrm{NH} 2 \mathrm{Cl}$ \\
\hline $\mathrm{Cr}$ & $17,60 \pm 0,44$ & $18,15 \pm 0,33$ & $17,03 \pm 0,01$ & $18,42 \pm 0,16$ \\
\hline $\mathrm{Mn}$ & $1,99 \pm 0,05$ & $2,16 \pm 0,30$ & $2,50 \pm 0,59$ & $1,92 \pm 0,22$ \\
\hline $\mathrm{Fe}$ & $71,85 \pm 0,02$ & $70,78 \pm 0,03$ & $70,75 \pm 0,21$ & $71,40 \pm 0,17$ \\
\hline $\mathrm{Ni}$ & $8,58 \pm 0,37$ & $8,90 \pm 0,08$ & $9,71 \pm 0,76$ & $8,27 \pm 0,20$ \\
\hline $\mathrm{Mo}$ & $0,00 \pm 0,00$ & $0,00 \pm 0,00$ & $0,00 \pm 0,00$ & $0,00 \pm 0,00$ \\
\hline $\mathrm{Cl}$ & $0,00 \pm 0,00$ & $0,00 \pm 0,00$ & $0,02 \pm 0,03$ & $0,00 \pm 0,00$ \\
\hline \multicolumn{5}{|c|}{ Сталь AISI 316 } \\
\hline $\mathrm{Cr}$ & $16,74 \pm 0,59$ & $16,34 \pm 0,18$ & $16,49 \pm 0,18$ & $16,00 \pm 0,58$ \\
\hline $\mathrm{Mn}$ & $1,95 \pm 0,53$ & $2,24 \pm 0,31$ & $1,88 \pm 0,13$ & $2,08 \pm 0,36$ \\
\hline $\mathrm{Fe}$ & $69,54 \pm 0,74$ & $69,00 \pm 0,87$ & $68,11 \pm 0,93$ & $68,09 \pm 0,90$ \\
\hline $\mathrm{Ni}$ & $11,33 \pm 0,30$ & $11,78 \pm 1,08$ & $12,67 \pm 1,03$ & $12,48 \pm 0,40$ \\
\hline $\mathrm{Mo}$ & $0,45 \pm 0,07$ & $0,57 \pm 0,15$ & $0,86 \pm 0,21$ & $1,35 \pm 0,32$ \\
\hline $\mathrm{Cl}$ & $0,00 \pm 0,00$ & $0,09 \pm 0,06$ & $0,00 \pm 0,00$ & $0,03 \pm 0,04$ \\
\hline
\end{tabular}

Из данных элементного анализа видно изменение в содержании металлов на поверхности. При этом для стали AISI 304 происходит вымывание в растворах $\mathrm{NaClO}$ и $\mathrm{Ca}(\mathrm{ClO})_{2}$ хрома и железа, а в раствоpe $\mathrm{NH}_{2} \mathrm{Cl}$ марганца, железа, никеля. Для стали AISI 316 происходит вымывание в растворе $\mathrm{NaClO}$ хрома, железа, как и в случае со сталью AISI 304. B растворе $\mathrm{Ca}(\mathrm{ClO})_{2}$ наряду с хромом и железом вымывается и марганец. При использовании раствора $\mathrm{NH}_{2} \mathrm{Cl}$ вымывается хром и железо в большей степени, чем в растворе $\mathrm{NaClO}$. Однако практически все изменения в элементном составе поверхности, как и содержание хлора, находятся в пределах погрешности прибора. Поэтому нельзя достоверно утверждать 0 нахождении хлора в составе продуктов 
Вестник Брестского государственного технического университета. 2021

взаимодействия растворов со сталью, а касательно миграции тяжелых металлов необходимо проведение более длительных исследований Таким образом, 1 цикл обработки сталей марок AISI 304 и AISI 316 не приводит к возникновению очагов коррозии, а также изменению состава стали, что обусловлено высокой коррозионной устойчивостью данного типа сталей за счет их легирования никелем и хромом. Однако интерес представляют долгосрочные исследования коррозии данных сталей, что и будет целью следующих исследований, с целью сравнительного анализы скорости миграции отдельных металлов.

\section{Выводы}

В представленной статье проводилась оценка коррозионной устойчивости нержавеющих сталей AISI 304 и AISI 316 в хлорсодержащих дезинфицирующих растворах. Были сделаны следующие основные выводы:

1. Согласно проведенным электрохимическим исследованиям в $2 \%$ растворах выбранных хлорсодержащих дезинфицирующих веществ наименее устойчивой является сталь AISI 304. Особенно в растворах $\mathrm{NH}_{2} \mathrm{Cl}$ и $\mathrm{NaClO}$.

2. После 1 цикла дезинфекции поверхностей сталей марок AISI 304 и AISI 316 появление очагов коррозии не наблюдается, а изменение состава их поверхности незначительно и находится в пределах погрешности прибора.

\section{Список цитированных источников}

1. Романовский, В. И. Коррозионная устойчивость углеродистых сталей к дезинсфицирующим растворам / В. И. Романовский, Ю. Н. Чайка // Труды БГТУ. - 2014 - № 3 (167): Химия и технология неорган. В-в. - С. 47-50.

2. Романовский, В. И. Коррозионная устойчивость стали 15 к дезинсиицирующим растворам / В. И. Романовский, В. В. Жилинский // Труды БГТУ. - 2015 - № 3 (176): Химия и технология неорган. в-В. - С. 29-34.

3. Romanovski V., Claesson P. M., Hedberg Y. S. Comparison of different surface disinfection treatments of drinking water facilities from a corrosion and environmental perspective // Environmental Science and Pollution Research. - 2020. doi.org/10.1007/s11356-020-07801-9.

4. Романовский, В. И. Сравнительный анализ коррозионной устойчивости углеродистых сталей к дезинфицирующим растворам электрохимическим методом / В. И. Романовский, В. В. Жилинский Ю. Н. Бессонова // Вестник БрГТУ. - 2016. - № 2 (98): Водохозяйственное строительство, теплоэнергетика и геоэкология. - С. 126-129.

5. Романовский, В. И. Анализ эффективности дезинфекции сооружений питьевого водоснабжения с использованием хлорсодержащих дезинфицирующих средств и озона / В. И. Романовский, М. В. Рымовская, Ю. Н. Бессонова, А. М. Ковалевская, В.В.Лихавицкий // Вестник БрГТУ. - 2015. - № 2 (92): Водохозяйственное строительство, теплоэнергетика и геоэкология. - С. 68-71.

6. Романовский, В. И. Сравнительный анализ эффективности дезинфекции сооружений водоснабжения дезинфицирующими растворами / В. И. Романовский, И. В. Рымовская, С. Янь Фэн // Вода magazine. - 2015. - № 10 (98). - C. 18-21.

7. Романовский, В. И. Определение основных параметров дезинфекции и обеззараживания озоном сооружений питьевого водоснабжения / В. И. Романовский, В.В.Лихавицкий, М. В. Рымовская, А. Д. Гуринович // Труды БГТУ. - 2015 - № 3 (176): Химия и технология неорган. В-в. - С. 108-112.

8. Романовский, В.И. Исследование растворимости озона в воде по высоте столба жидкости / В. И. Романовский, В. В. Лихавицкий, А. Д. Гуринович // Труды БГТУ. - 2015. - № 3 (176): Химия и технология неорган. В-В. - С. 113-118.

9. Романовский, В. И. Технические аспекты использования озона в водоподготовке / В. И. Романовский, А. Д. Гуринович, Ю. Н. Бессонова, Е.В. Крышилович // Вода magazine. - 2016. - №2 (102). C. $36-41$.

10. Гуринович, А. Д. Эффрективность дезинфекции озоном сооружений систем водоснабжения / А. Д. Гуринович, В.И.Романовский, Ю. Н. Бессонова // Водоочистка. Водоподготовка. Водоснабжение. - 2016. - № 10. - С. 48-51.

11. Романовский, В. И. Сравнительный анализ расчета показателей эколого-экономической эффективности способов дезинфеекции водозаборных скважин / В. И. Романовский, А. Д. Гуринович // Актуальные вопросы экономики строительства и городского хозяйства: материалы II междунар. науч.-практ. конф., Минск, 23-24 апр., 2013 / Белорусский национальный технический университет; редкол.: С. А. Пелих, В. К. Липский. - Минск, 2014. - С. 300-306.
12. Pardo, A. Effect of Mo and Mn additions on the corrosion behaviour of AISI 304 and 316 stainless steels in H2SO4 / A. Pardo, M. C. Merino, A. E. Coy, F. Viejo, R. Arrabal, E. Matykina // Corrosion Science. 2008. - Vol. 50(3). - P.780-794.

13. El Gammudi, B. A. (2008) Microscopic study of bacterial attachment on AISI 304 and AISI 316 stainless steel surfaces / B. A. El Gammudi, I. M. El Musrati, A. M. Bourgheya, A. A. El Tawil, J. Telegdi // International Journal of Integrative Biology - 2008. - Vol. 4(2). - P. 72.

14. Noble, J. Nickel allergy and orthodontics, a review and report of two cases / J. Noble, S. I. Ahing, N. E. Karaiskos, W. A. Wiltshire // British Dental Journal. - 2008. - Vol. 204. - №. 6. - P. 297-300.

\section{References}

1. Romanovskij, V. I. Korrozionnaya ustojchivost' uglerodistyh stalej k dezinficiruyushchim rastvoram / V. I. Romanovskij, YU. N. CHajka /I Trudy BGTU. - 2014 - № 3 (167): Himiya i tekhnologiya neorgan. v-v. - C. 47-50.

2. Romanovskij, V. I. Korrozionnaya ustojchivost' stali $15 \mathrm{k}$ dezinficiruyushchim rastvoram / V. I. Romanovskij, V. V. ZHilinskij // Trudy BGTU. 2015. - № 3 (176): Himiya i tekhnologiya neorgan. v-v. - C. $29-34$.

3. Romanovski V., Claesson P. M., Hedberg Y. S. Comparison of different surface disinfection treatments of drinking water facilities from a corrosion and environmental perspective // Environmental Science and Pollution Research. - 2020. doi.org/10.1007/s11356-020-07801-9.

4. Romanovskij, V. I. Sravnitel'nyj analiz korrozionnoj ustojchivosti uglerodistyh stalej $\mathrm{k}$ dezinficiruyushchim rastvoram elektrohimicheskim metodom / V. I. Romanovskij, V. V. ZHilinskij, YU. N. Bessonova // Vestnik BrGTU. - 2016. - № 2 (98): Vodohozyajstvennoe stroitel'stvo, teploenergetika i geoekologiya. - S. 126-129.

5. Romanovskij, V. I. Analiz effektivnosti dezinfekcii sooruzhenij pit'evogo vodosnabzheniya $s$ ispol'zovaniem hlorsoderzhashchih dezinficiruyushchih sredstv i ozona / V. I. Romanovskij, M. V. Rymovskaya, YU. N. Bessonova, A. M. Kovalevskaya, V. V. Lihavickij // Vestnik BrGTU. - 2015. - № 2 (92): Vodohozyajstvennoe stroitel'stvo, teploenergetika i geoekologiya. - S. 68-71.

6. Romanovskij, V. I. Sravnitel'nyj analiz effektivnosti dezinfekcii sooruzhenij vodosnabzheniya dezinficiruyushchimi rastvorami / V. I. Romanovskij, I. V. Rymovskaya, S. YAn' Fen // Voda magazine. - 2015. № 10 (98). - S. 18-21.

7. Romanovskij, V. I. Opredelenie osnovnyh parametrov dezinfekcii obezzarazhivaniya ozonom sooruzhenij pit'evogo vodosnabzheniya I V. I. Romanovskij, V. V. Lihavickij, M. V. Rymovskaya, A. D. Gurinovich // Trudy BGTU. - 2015 - № 3 (176): Himiya i tekhnologiya neorgan. v-v. - C. 108-112.

8. Romanovskij, V. I. Issledovanie rastvorimosti ozona v vode po vysote stolba zhidkosti / V. I. Romanovskij, V. V. Lihavickij, A. D. Gurinovich /I Trudy BGTU. - 2015. - № 3 (176): Himiya i tekhnologiya neorgan. v-v. C. $113-118$.

9. Romanovskij, V. I. Tekhnicheskie aspekty ispol'zovaniya ozona v vodopodgotovke / V. I. Romanovskij, A. D. Gurinovich, YU. N. Bessonova, E.V. Kryshilovich // Voda magazine. - 2016. - №2 (102) - S. 36-41.

10. Gurinovich, A. D. Effektivnost' dezinfekcii ozonom sooruzhenij sistem vodosnabzheniya / A. D. Gurinovich, V. I. Romanovskij, YU. N. Bessonova // Vodoochistka. Vodopodgotovka. Vodosnabzhenie. - 2016. № 10. - S. 48-51.

11. Romanovskij, V. I. Sravnitel'nyj analiz rascheta pokazatelej ekologoekonomicheskoj effektivnosti sposobov dezinfekcii vodozabornyh skvazhin / V. I. Romanovskij, A. D. Gurinovich // Aktual'nye voprosy ekonomiki stroitel'stva i gorodskogo hozyajstva: materialy II mezhdunar. nauch.-prakt. konf., Minsk, 23-24 apr., 2013 / Belorusskij nacional'nyj tekhnicheskij universitet; redkol.: S. A. Pelih, V. K. Lipskij. - Minsk, 2014. - S. 300-306.

12. Pardo, A. Effect of $\mathrm{Mo}$ and $\mathrm{Mn}$ additions on the corrosion behaviour of AISI 304 and 316 stainless steels in H2SO4 / A. Pardo, M. C. Merino, A. E. Coy, F. Viejo, R. Arrabal, E. Matykina // Corrosion Science. 2008. - Vol. 50(3). - P.780-794.

13. El Gammudi, B. A. (2008) Microscopic study of bacterial attachment on AISI 304 and AISI 316 stainless steel surfaces / B. A. El Gammudi, I. M. El Musrati, A. M. Bourgheya, A. A. El Tawil, J. Telegdi // International Journal of Integrative Biology - 2008. - Vol. 4(2). - P. 72.

14. Noble, J. Nickel allergy and orthodontics, a review and report of two cases / J. Noble, S. I. Ahing, N. E. Karaiskos, W. A. Wiltshire // British Dental Journal. - 2008. - Vol. 204. - №. 6. - P. 297-300.

Материал поступил в редакцию 28.05.2021 